\title{
Effective Lecturing
}

\author{
Habib MA
}

It is a popular belief that most students who attended conventional lecture-based course don't end up with a good understanding of the fundamental concepts. Yet we can't avoid this method of instruction in the curriculum of professional courses. In the present undergraduate medical curriculum of Bangladesh, $42.9 \%$ of the total 3498 teaching hours (excluding practice days) is for lecture ${ }^{1}$. In fact 'Lecturing comes so natural to mankind that it is hard to stop it by edict'. Instead of merely criticising lectures, endeavour should be made to improve them and attention should be paid to the reasons for the criticism.

Teachers are always trying to adopt newer technologies as instructional aids to make their classes more effective. Simultaneously their studies have worked out long list of do's and don'ts for using the technology ${ }^{3}$. In 1980, Paegle et al. reported a comparative study of effect of traditional lecture using transparencies and same information via closed-circuit television (CCTV). The author observed no significant difference in test result. But it is interesting to note that students in their comment preferred lecture format significantly $(p<0.0003)^{4}$, indicating that it is required to be rational in selecting student friendly instructional and effective aids.

To increase the students' involvement different forms of inter-active lecturing have been integrated in courses worldwide $^{5}$. A good lecture usually provides opportunities for student comments, questions and sustained dialectical exchange. Side by side, it demands listening, remembering, tracking arguments, judicious note-taking and thinking about what is said in light of assigned reading from the students.

Concept of Dual-Lecture Modes in medical education has drawn attention. During the lecture, lecturers teach the same topics but from different perspectives. A histologist presents histological terms and interprets normal microscopic structures, while a pathologist integrates clinical cases, presents and interprets pathological changes and findings at the same time. Compared to traditional teaching given by one lecturer, dual-lecturer-mode is observed more effective in delivering contents and more appreciated by senior students ${ }^{6}$.

Students' tendency to remain absent in the lecture class is always a subject of concern. Survey involving students identified time table of lecture as primary factor, but quality of lecture and presence of the same lecture in electronic media were also identified as important factors ${ }^{7}$. Of course counter opinions are there regarding making availability of slides before lectures ${ }^{8}$. Students rather prefer to receive lecture slides before class, though many instructors are less pronounced in their preferences. Having access to handouts of the slides during lecture is associated with a number of benefits: less note-taking, less time needed to prepare for a final test and better performance on the final test. The dark side of this should also be kept in mind that this may reduce opportunity to cultivate students' own independent learning. A study on the pre-clinical medical students revealed that only $4.7-9.7 \%$ of the students who were provided handouts read textbooks after lectures and before examinations ${ }^{9}$. But reading is one of the important skills for medical students.

With the advancement of technology the lectures are not now confined to a well decorated lecture gallery only. In the digital environment lecture captures and synchronized multimedia contents are widely available. Survey showed that the students liked those. But outcome evaluation indicated that those could be useful supplements for live lectures and even be substitute in case no live lectures were being held ${ }^{10,11}$. The quality of the lecturer is a key factor in student decisions regarding live lecture attendance. Students use recorded lectures both as a replacement for live lectures and as a supplement to live lectures ${ }^{12,13}$.

Nowadays, technology is invading in every classroom of medical education. Acceptance is the requirement of the time. Tuebingen's Sectio Chirurgica (TSC) is an innovative, interactive, multimedia, and transdisciplinary teaching method designed to complement dissection courses. The TSC allows clinical anatomy to be taught

Brig Gen Md Ahsan Habib, MBBS, M Phil, MMEd, Professor and Head, Department of Anatomy, AFMC, Dhaka. 
via interactive live stream. Study revealed that students who attended the TSC demonstration in addition to the dissection course showed significantly better outcome than students who did not attend the $\mathrm{TSC}^{14}$.

In this era of paradigm shift from teacher-centered to learner-centered classrooms in medical education, lecture is still the most popular method of instruction as it is economical and efficient method of conveying information to large groups of students. If delivered with clarity, interest and persuasion lectures can be as effective as other methods of teaching at imparting information and explaining. This issue of Journal of Armed Forces Medical College has published report of an original research conducted by Rahman MM et. al.

The researchers observed the lectures and also collected views of students to assess the medical teachers' skill in instructional events which are well accepted internationally and the study revealed that teachers were not practicing some of the important skill adequately, like expressing lesson objective at the beginning, legibility of teaching aids and providing good summary at the end. But those skills are very much required to make a lecture effective. Hope this paper will be able to give reader a practical scenario of lecture standard of medical education of Bangladesh and will help the teachers to find self position, thereby improving their status.

\section{References}

1. Bangladesh Medical and Dental Council. Curriculum for Under-graduate medical education. Dhaka : Directorate General Health Service; 2012.

2. Costin F. Lecturing versus Other Methods of Teaching: A Review of Research. British Journal of Educational Technology 1972; 3(1): 4-31.

3. Simpson C L, Pollacia L, Speers J, Willis TH, Tarver R. An analysis of certain factors related to the use of PowerPoint. Communications of the International Information Management Association 2003; 3: 73-83.

4. Paegle RD, Wilkinson EJ, Donnelly MB. Videotaped vs traditional lectures for medical students. Medical Education 1980; 14, 387-93.
5. Jen A, Webb EM, Ahearn B, Naeger DM. Lecture Evaluations by Medical Students: Concepts That Correlate With Scores. Journal of the American College of Radiology 2016; 13(1) : 72-6.

6. Chen J, Daley WP, Yang G, Cui D. Comparison of Mono-Lecture and Dual-Lecture Modes in the First Year Medical Education. The FASEB Journal 2016; 30(1) : Supl 785.13.

7. Davis EA, Hodgson Y, Macaulay JO. Engagement of Students with Lectures in Biochemistry and Pharmacology. Biochemistry and Molecular Biology Education 2012; 40 ( 5): 300-9.

8. Pelloux S, Kirmizigul P, Lermusiaux PP. Availability of slides before lectures does not decrease attendance at lectures. Medical Teacher 2015; 37:8, 793.

9. Dharmasaroja P. Do medical students really need lecture handouts? Medical Teacher 2014; 36: 914-5.

10. Pale P, Petrovic J, Jeren B. Assessing the learning potential and students' perception of rich lecture captures. Journal of Computer Assisted Learning 2014, 30: 187-95.

11. Maloney E, Hippe DS, Paladin A, Chew FS, Alice S. Musculoskeletal Ultrasound Training for Radiology Residents: Lecture Versus Interactive Learning Module. Academic Radiology 2016 (in press : doi:10.1016/j.acra. 2015.11.018).

12. Gupta A, Saks NS. Exploring medical student decisions regarding attending live lectures and using recorded lectures. Medical Teacher 2013; 35: 767-71.

13. Pam MF, Andrew C. Comparison of the Effectiveness of Interactive Didactic Lecture Versus Online Simulation-Based CME Programs Directed at Improving the Diagnostic Capabilities of Primary Care Practitioners. Journal of Continuing Education in the Health Professions 2016; 36(1): 32-7.

14. Shiozawa T, Butz B, Herlan S, Hirt B. Interactive anatomical and surgical live stream lectures improve students' academic performance in applied clinical anatomy. Anatomical Sciences Education 2016 (in press: DOI: 10.1002/ase.1623). 